\title{
Primary non-skeletal intracranial cartilaginous neoplasms: report of a chondroma and a mesenchymal chondrosarcoma
}

\author{
WILLIAM Q. WU AND ANGELO LAPI \\ From the Departments of Surgery (Neurosurgery) and Pathology, St. Mary's Hospital, Kansas City, \\ Missouri, U.S.A.
}

SUMMARY The clinical and pathological features of two rare, primary non-skeletal intracranial cartilaginous tumours, a chondroma and a mesenchymal chondrosarcoma, are presented. The literature with respect to clinical, pathological, and possible pathogenetic features is reviewed. The chondroma was successfully resected and the patient has had no recurrence since the operation in 1956. The clinical course of the mesenchymal chondrosarcoma was characterized by rapidly recurring tumour, slowed somewhat by cobalt therapy and frequent surgical interventions. Death occurred some 16 months after the initial resection. There were no metastases.

Primary intracranial cartilaginous neoplasms which do not arise from bones of the skull are extremely rare (Alpers, 1935; Chorobski, Jarzymski, and Ferens, 1939; Dahlin and Henderson, 1962; Flyger, Freidenfeldt, and Orell, 1963; Siris and Angrist, 1942). We report herein two such tumours; one benign and the other malignant.

\section{CASE 1: CHONDROMA}

During the seventh month of pregnancy L.W., a 32-yearold white woman, began to exp=rience fainting spells of 15 minutes' duration followed by increasingly severe speech difficulty and weakness in the right arm. She was admitted to the hospital approximately one month after delivery, or three months after the onset of symptoms, at which time she was having generalized convulsions, bit her tongue, and lost consciousness for a 30 minute period.

The past history, family history, and system review were negative or non-contributory except as related to the present illness.

Physical examination revealed a well-developed, wellnourished, white female with mild speech slurring. There was a contusion in the right frontal region of the scalp.

The fundi showed slight blurring of the nasal and upper disc margins and the pupils were equal and reacted to light. Right hemiparesis with hyperactive reflexes on the right was present. Hoffman's sign was positive on the right, but the Babinski reaction was negative. There was no astereognosis.

Moderate nasal obstruction with yellowish nasal discharge was noted. Artificial dentures were well-fitting and oral hygiene was good. The breasts were full and lactating. The physical examination was otherwise negative and the blood pressure was $130 / 70 \mathrm{~mm} \mathrm{Hg}$.

Radiographs of the skull showed a shell-like calcification on the left just posterior to the coronal suture and in the region of the middle meningeal vessels, the grooves of which appeared more pronounced on the left. The adjacent skull was thickened, but the falx, although calcified, was not shifted. The sella was intact.

A left carotid arteriogram showed an abnormal vascular pattern in the left parietal area adjacent to the skull. Ventriculography disclosed downward displacement of the lateral, superior portion of the left lateral ventricle. It was also somewhat blunted and dilated, and its roof flattened along the anterior one half. The third ventricle was displaced to the right, but not dilated.

All laboratory findings were within normal limits.

Craniotomy was performed nine days after admission, revealing a firm, avascular, smooth, bosselated tumour in the left parietal area measuring $8.5 \times 6.5 \times 4 \mathrm{~cm}$. The dura was firmly adherent to the convex surface of the subjacent tumour and to the overlying bone which showed hyperostosis. The deep surface of the tumour was smooth, irregular and somewhat concave. The tumour displaced but did not invade brain tissue, after the fashion of a meningioma. It weighed $160 \mathrm{~g}$, varied from bluish to grayish white and showed only slight translucence. Because of its size and unyielding characteristics the tumour was removed by partial morsellation (Fig. 1).

Histologically, the tumour consisted largely of mature hyaline cartilage with only an occasional eosinophilic immature area (Fig. 2). Portions of the convex surface were covered with dura. The pathological diagnosis was chondroma, probably originating in the meninges. 


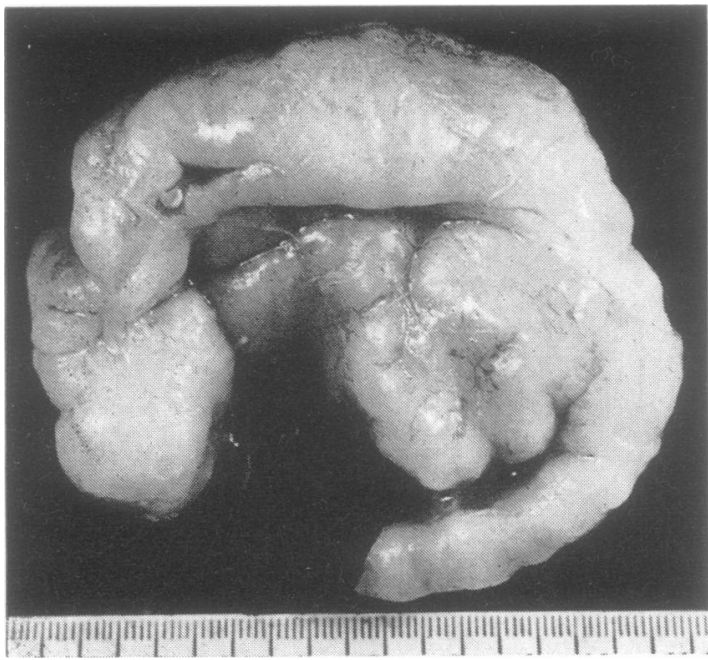

FIG. 1. Case 1, concave (deep) surface.

Except for episodes of increased CSF pressure during the first three weeks post-operatively, convalescence was relatively uneventful and the patient has required no further surgery since 1956. At the present time she cares for five children and helps run the farm, frequently operating a tractor.
CASE 2: MESENCHYMAL CHONDROSARCOMA

S.J., an 18-year-old white girl, had complained of occipital headaches for several months, and 10 days before admission to the hospital developed stiffness in the muscles of the right side of the neck and of the right leg. Three days before admission she complained of nausea, projectile vomiting, and lethargy. In the past she had been involved in two automobile accidents but had escaped physical injury.

Her father suffered from migraine headaches but otherwise the personal and family history and review of systems were of no significance.

On physical examination she appeared as a torpid, but responsive, well-developed and well-nourished white female who seemed somewhat withdrawn.

The right pupil was larger than the left and the discs were choked 2 plus dioptres. There was impairment of external ocular movements on the right.

The neck muscles were slightly tender and there was slight weakness of the left extremities. All deep tendon reflexes were sluggish but equal. The plantar reflexes were equivocal. The chest and heart were normal and the blood pressure was $110 / 70 \mathrm{~mm} \mathrm{Hg}$.

Except for a haemoglobin of $11.7 \mathrm{~g} / 100 \mathrm{ml}$., the laboratory investigation was negative.

Skull radiography disclosed an area of finely stippled calcification in the left fronto-parietal area measuring 5 $6.6 \mathrm{~cm}$ and with evidence of increased intracraniaib 8 pressure (Fig. 3).

Carotid angiography revealed slight anterior displacee

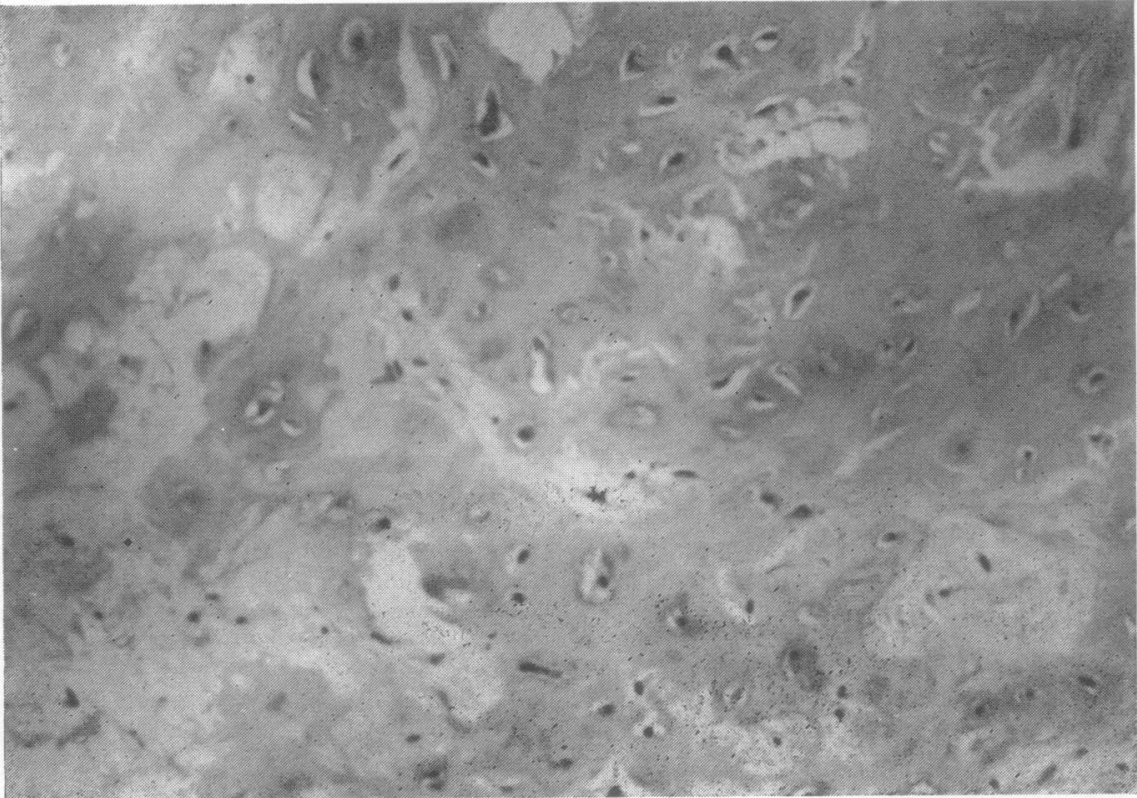

FIG. 2. Histological appearance in case 1 consisting uniformly of hyaline cartilage. $H$. and $E ., \times 300$. 


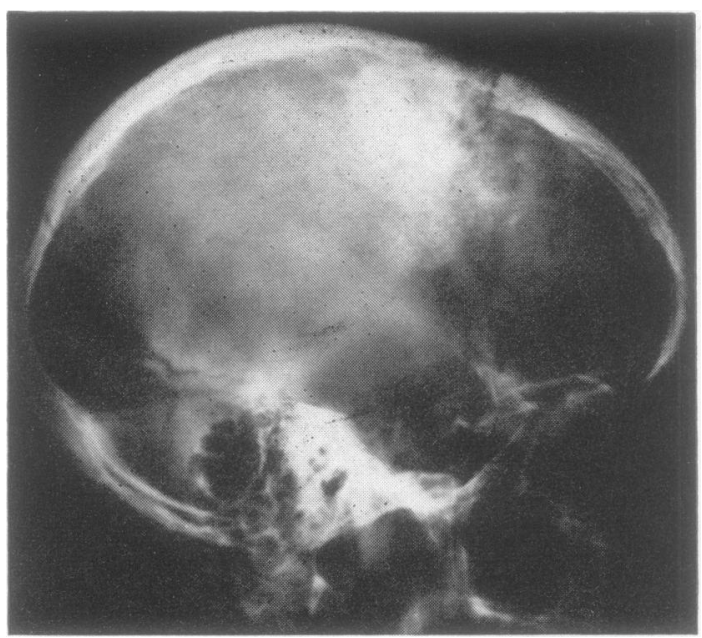

FIG. 3. Finely stippled calcification in tumour in the left fronto-parietal area (case 2).

ment of the forward portions of the anterior cerebral arteries and displacement of the middle and posterior portions of the left cerebral artery across the midline and downward into the right hemisphere. Vessels arising from the anterior cerebral arteries were seen entering the highly vascular calcified area. Vessels of the Sylvian group were displaced downward. The radiographic diagnosis was tumour mass in the left fronto-parietal area, extending across the midline.

At surgery increased bleeding from the overlying, adherent bone was encountered when the periosteum was stripped. Initially, only a small area of tumour presented on the surface of the brain, but exploration disclosed much more tumour, deeply placed within the left cerebral hemisphere, and extending across the midline in 'iceberg' fashion. Portions of the attached overlying dura and bone were resected with the tumour, the periphery of which was highly vascular. Excision was incomplete due to the widespread infiltration of the tumour. The defect was closed with dura substitute and an acrylic plate.

Pathological studies showed a moderately firm, grayishwhite tumour measuring $10.4 \times 6.5 \times 5.5 \mathrm{~cm}$ and weighing $176 \mathrm{~g}$. It presented a convex, smooth surface with bosselations up to $1 \mathrm{~cm}$ in diameter and a flat, granular surface with calcified foci. Soft, reddish, friable areas were scattered throughout.

A portion of parietal bone measuring $12 \times 7 \cdot 2 \mathrm{~cm}$ was also received and showed invasive tumour near the centre of the concave surface over an area $4 \mathrm{~cm}$ in diameter.

Microscopically there were solid, cellular areas consisting of small, round, oval, polygonal, or spindle-shaped cells with hyperchromatic nuclei often arranged in the form of irregular sheets and band-like masses. Perivascular clustering of tumour cells was common (Fig. 4). The cytoplasm was scanty and clear and mitoses were common. Cleft-like spaces lined by endothelium were occasionally seen, but otherwise the pattern was relatively uninterrupted and with scanty stroma. Sometimes a villous pattern was evident, not unlike that seen in giant osteoid osteoma and in a few limited areas giant or bizarre nuclei were prominent. In other areas there were foci of fairly mature hyaline cartilage with calcified centres. Osteoid tissue was common in some areas (Fig. 5).

The tumour in the parietal bone showed many cartilaginous areas. The pathological diagnosis was mesenchymal chondrosarcoma ${ }^{1}$.

The post-operative course was fairly smooth, but although there was no neurological deficit the patient was depressed, confused, and disoriented at the time of discharge, 11 days post-operatively.

During the subsequent 14 months there were four hospital admissions and three surgical interventions, interspersed with cobalt therapy because of clinical evidence of increased intracranial pressure. Yet, after each craniotomy there was clinical improvement and the patient remained mentally clear until three days before death or about five weeks after the last operation. (In the case reported by Dahlin and Henderson (1962) there were five surgical procedures over a six year span and in the case of Dowling (1964) the patient survived nine years.)

Terminally, the size of the mass in the left calvarium was approximately half the total size of the head. The findings at operations included variously invasive tumour, cysts, serous fluid, blood clots, and oedema. With each subsequent resection the tumour appeared more medullary and anaplastic, and finally, at the last operation and at necropsy, neither cartilage nor osteoid could be demonstrated in the tumour. Death occurred almost 16 months after the first operation, and at necropsy somewhat more than $100 \mathrm{~g}$ of tumour tissue was found at the operative site together with a lentil-shaped haematoma measuring $6 \times 10 \mathrm{~cm}$. Several oedematous, infarcted areas were seen in the adjacent brain tissue. The tumour had invaded the left lateral and third ventricles and destroyed the left thalamus. The sella was flattened and widened.

The necropsy elsewhere disclosed poorly developed secondary sexual characteristics with small, flat breasts, hairy abdomen and extremities, and male type escutcheon.

\section{DISCUSSION}

BENIGN TUMOURS The infrequency of intracranial cartilaginous tumours is emphasized by the fact that Cushing (1931) mentioned only three cartilaginous tumours in his series of 2,000; Dowman and Smith (1928) found none in 100; Leitholf (1956) reported four in 4,399; and Van Wagenen (1934) none in 149 brain tumours. According to Flyger et al. (1963) a total of $\mathbf{4 0}$ chondromatous or osteochondromatous primary intracranial tumours had been reported

'Dr. David Dahlin was kind enough to review the slides and confirm the diagnosis. 


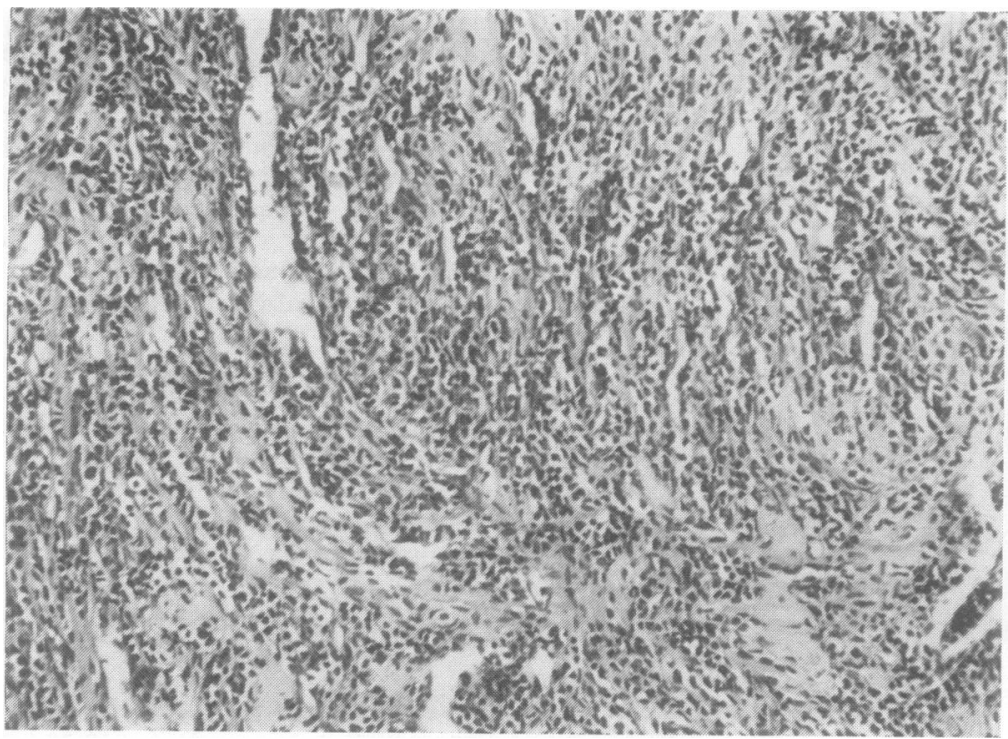

FIG. 4. Cellular areas in case 2. $H$. and $E$., $\times 70$.

before 1963. Sporadic reports occurred early in this century (Bevan and Gill, 1919) and in the past three decades there have been only a few isolated reports of such tumours (Smitt, 1929; Brütt, 1931; Froment, Wertheimer, and Dechaume, 1932; Verbrugghen and Learmonth, 1932; Austoni, 1936; Baker and Adams, 1937; Chorobski et al., 1939; Siris and Angrist, 1942; Money, 1943; Forsythe, Baker, Dockerty, and Camp, 1947; Obrador and Soto, 1953; David and Constans, 1957; Leitholf, (1956) quoted by Roukkula, 1964; Lichtenstein, and
Bernstein, 1959; Flyger et al., 1963; and Roukkula, $\underset{\omega}{\omega}$ 1964).

David and Constans found 22 pure chondromas of the convexity and added the 23rd in 1957. Since that time, and including our case, three more have been added (Gorman, 1960; Ramamurthi, Iyer, anc Vedachalam, 1961; Geuna and Gori, 1962) for a total of 29. In the English literature, Chorobski and co-workers and Money contributed most witls on respect to chondroma.

The pathological and clinical features of benign

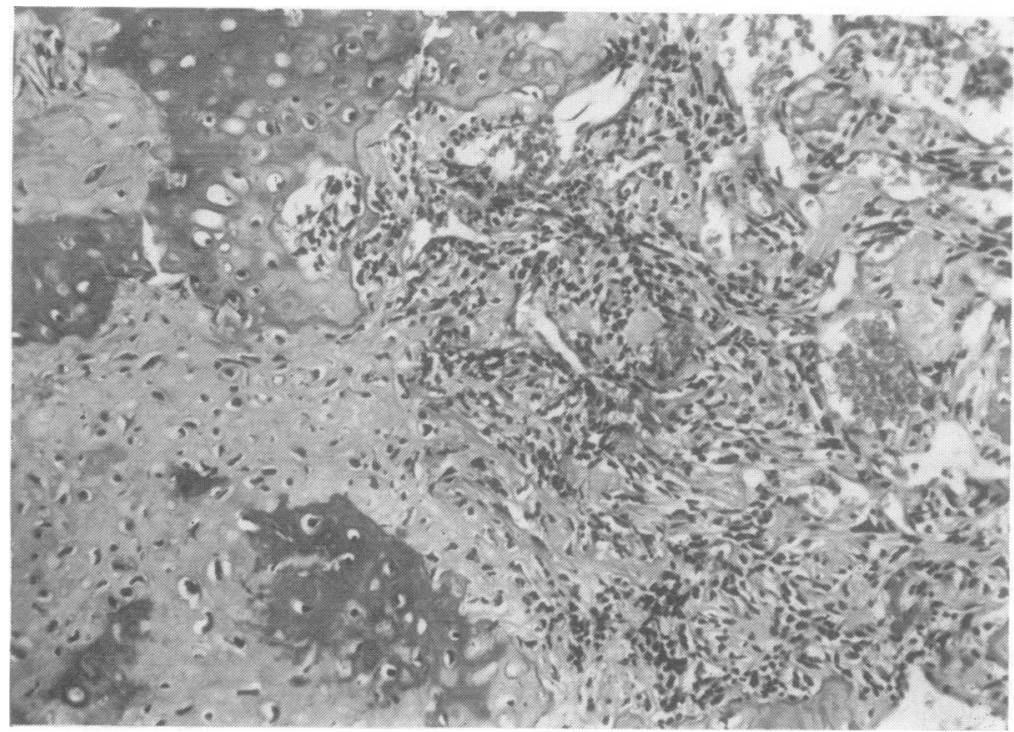

FIG. 5. Cellular and chondroid areas in case 2 with foci of osteoid tissue. $H$. and $E$., $\times 70$. 
intracranial cartilaginous tumours are summarized by Flyger et al. (1963) as follows: 'They occur principally in males age 18 to 65 , some originate in the base of the skull, but some are not connected with skull bones. Almost all are attached to the dura or falx, but sometimes there is no demonstrable connection with the meninges. The majority are highly differentiated and encapsulated chondromas. Osteochondromas are less common. Some contain fibromatous or meningeomatous elements. They are often calcified and radiopaque. Growth is relatively slow.'

Coley and Higinbotham (1949) emphasize the propensity of chondromas to undergo malignant change just as chondromas in large bones sometimes do and as happened in Alper's case. Other authors have noted that tumours of the convexity are larger than those of the base due to lack of early symptoms. The most frequent complaints in this group include Jacksonian seizures, hemiparesis, and findings associated with increased intracranial pressure. Impairment of certain cranial nerves may also be present, but because of the insidious involvement, diagnosis is usually made late when the tumour is of advanced size. The clinical manifestations of chondromas of the base have been described separately by List (1943) and Klingler (1951). Of the medial tumours the suprasellar lesion will cause visual defects such as bitemporal hemianopsia, optic atrophy, and diminished visual acuity due to compression of the optic chiasm and optic tracts.

Some tumours may extend to the hypothalamohypophyseal region to give rise to the diencephalic syndrome characterized by obesity, polyuria, amenorrhoea, somnolence, and impotence. The parasellar chondroma most frequently compromises the sixth, third, fifth, and fourth cranial nerves in that order, but paralysis of the third nerve may be incomplete. Diminished corneal reflex and pain in the ophthalmic region have been observed in these lesions.

A tumour of the middle fossa may reach such size as to produce contralateral hemiparesis. Extension of such a tumour to the posterior fossa may involve the eighth nerve to produce surdity and vertigo. Chondromas of the retrosellar region and those having origin from the lesser wing of the sphenoid bone also affect the sixth nerve as a first sign of their presence as well as manifesting unilateral exophthalmos.

MALIGNANT TUMOURS Lichtenstein and Bernstein (1959), Dahlin and Henderson (1962), Dowling (1964), and Raskind and Grant (1966), have reported mesenchymal chondrosarcomas. According to Dowling the average age at the time of diagnosis is 33. This contrasts with the median of 55 years for chondrosarcomas in general (O'Neal and Ackerman, 1952). Males predominate 2 to 1 (Dahlin and Henderson, 1962). These tumours have originated in various bones, the meninges, and the temporal muscle, but involve the long bones less frequently than the usual chondrosarcoma.

Dahlin and Henderson (1962) found nine mesenchymal chondrosarcomas among approximately 3,000 histologically verified primary neoplasms of bone representing a time span of 55 years at the Mayo Clinic. In the same series were 281 chondrosarcomas and 115 chondromas, indicating the rarity of this tumour. They characterized mesenchymal chondrosarcomas as a well defined, firm, and partly calcified tumour. 'The cells are undifferentiated and a unique feature is the combination of innocuous appearing chondroid foci and a highly undifferentiated background of small cells. Mature bone or calcific foci may be seen. Perivascular clustering of tumor cells is common. Metastases are usually widespread, may occur at any site, even after long intervals (22 years in one of their cases), and resemble the original tumor.'

In our case, there were no metastases and the tumour terminally and at necropsy contained neither cartilage nor osteoid, such as were found initially, but only undifferentiated tumour cells.

Our case represents the third primary, intracranial, mesenchymal chondrosarcoma, the other two being the cases of Dahlin and Henderson and of Dowling.

PATHOGENESIS Various explanations for ectopic cartilage in brain and meninges have included embryonal rests displaced from the base of the skull or along the paths of migrating blood vessels (Chorobski et al., 1939; Money, 1943; David and Constans, 1957), metaplasia from fibroblasts (Brütt, 1931; Froment et al., 1932; Van Wagenen, 1934; Alpers, 1935; Baker and Adams, 1937; Cushing and Eisenhardt (1938), quoted by Flyger et al., 1963; or formation de novo from multipotent cells of the meninges or choroid plexus such as might give rise to a teratoma (Maximow and Bloom, 1942; Maximow, 1952).

Chorobski et al. (1939) apparently prefer the view that embryonal cartilage cells displaced by dysontogenesis give rise to chondromatous tumours, a variety of meningioma. Siris and Angrist (1942) considered theirs a chondroblastic meningioma.

It is suggested by Forsythe and his group (1947) that, by a process of metaplasia, the fibroblast secretes chondromucin or osseomucin instead of collagen and is thus capable of forming cartilage or bone.

Experimentally ectopic cartilage has been pro- 
duced by Stephenson (1952) by means of injection of alcoholic and other extracts of cartilage and bone into rabbits and by transplanting epithelium into the rectus muscles of dogs and rats. Grobstein and Parker (1954) produced cartilage in vitro in the mouse somite mesoderm by adding embryonic spinal cord. When combined in culture with pieces of spinal cord from the same stage embryos mesoderm differentiated into cartilage nodules.

Inasmuch as four papers (Brütt, 1931; Verbrugghen and Learmonth, 1932); Siris and Angrist, 1942; Dowling, 1964) report head injuries preceding three intracranial cartilaginous tumours and a similar tumour of muscle (fracture of skull, frequent football injuries of the head, shrapnel in skull, and contusion of the temporal area, respectively), it is interesting that Girgis and Pritchard (1958) produced cartilage experimentally during the repair of fractures of the skull vault in rats. They state that bone and cartilage have a common cellular origin and that ischaemia stimulates proliferating osteogenic cells to form cartilage instead of bone. Pressure and shearing stresses also favour cartilage over bone. In our chondroma there was a definite hyperostosis in the calvarium immediately adjacent to the tumour mass but there was no history of trauma.

\section{REFERENCES}

Alpers, B. J. (1935). Cerebral osteochondroma of dural origin. Ann Surg., 101, 27-37.

Austoni, B. (1936). Contributo Allo Studio Degli Encondromi Della Dura Madre Encefalica. Arch. ital. Chir., 44, 271-291.

Baker, A. B., and Adams, J. M. (1937) Primary fibroblastoma of brain. Report of case. Amer. J. Path., 13, 129-137.

Bevan, A. D., and Gill, J. C. (1919). Ossifying enchondroma of the brain. Surg. Clin. Chic., 3, 1109-1116.

Brütt, H. (1931). Intracranielles chondrom als hirntumor. Dtsch.Z. Chir., 231, 497-503.

Chorobski, J., Jarzymski, J., and Ferens, E. (1939). Intracranial solitary chondroma. Surg. Gyn. Obst. 68, 677686.

Coley, B. L., and Higinbotham, N. L. (1949). The significance of cartilage in abnormal locations. Cancer, 2, 777-788.

Cushing, H. (1931). Une série de deux mille cas de tumeurs intracraniennes verifiées histologiquement. Rev. neurol., $2,378$.

Cushing, H., and Eisenhardt, L. (1938). (Quoted by Flyger et al., 1963.) Meningiomas. Their Classification, Regional Behaviour, Life History and Surgical End Results. Thomas: Springfield.

Dahlin, D. C., and Henderson, E. D. (1962). Mesenchymal chondrosarcoma. Further observations on a new entity. Cancer (Philad.), 15, 410-417.

Dandy, W. E. (1933). Benign encapsulated tumors in lateral ventricles of the brain, diagnosis and treatment. Ann. Surg., 98, 841-845.

David, M., and Constans, J. P. (1957). Les chondromes intracraniens, à propos de deux nouveaux cas de chondromes primitifs du crane. Sem. Hop. Paris, 33, 1195-2014.

Dowling, E. A. (1964). Mesenchymal chondrosarcoma. J. Bone Jt Surg., 46A, 747-754.

Dowman, C. E., and Smith, W. A. (1928). Intracranial tumors; review of 100 verified cases. Arch. Neurol. Psychiat (Chic), 20, 1312-1329.

Flyger, G., Freidenfeldt, H., and Orell, S. R. (1963). Intracerebral, possibly malignant, osteochondrofibroma in a child. Acta path. microbiol. scand., 58, 299-305.

Forsythe, R. W., Baker, G. S., Dockerty, M. B., and Camp, J. D. (1947) Intracranial osteochondroma. Proc. Mayo Clin., 22, 350-356.

Froment, J., Wertheimer, P., and Dechaume, J. (1932). Chondrome de la faux du cerveau. Lyon méd., 150. 356-359.

Geuna, E., and Gori, G. (1962). Condroma della votta vanica. Minerva neurochiro, 6, 62-66.

Girgis, F. G., and Pritchard, J. J. (1958). Experimental production of cartilage during the repair of fractures of the skull vault in rats. J. Bone Jt Surg., 40B, 274-281.

Gorman, R. F. (1960). Intracranial chondroma. Aust N.Z.J. Surg., 30, 73-75.

Grobstein, C., and Parker, G. (1954). In vitro induction of cartilage in mouse somite mesoderm by embryonic spinal cord. Proc. Soc. exp. Biol. Med., 85, 477-481.

Klingler, M. (1951). Über Knorpelgeschwülste đer Schädelbasis mit intralcranieller Ausdehnung. Extension. Acta neurochir., 1, 337-380.

Leitholf, O. (1956). (Quoted by Roukkula, 1964). Tumaren der Schäđelknochen. Acta Neurochir. (Wien), 4, 287-ণ 319.

Letterer, E. (1920). (Quoted by Alpers, 1935). Über heterotope Geschwülste der Aderhaut geflechte. Beitr. path. Anat., 67, 370.

Lichtenstein, L., and Bernstein, D. (1959). Unusual benign and malignant chondroid tumors of bone. A survey of some mesenchymal cartilage tumors and malignant chondroblastic tumors, including a few multicentric ones, as well as many atypical benign chondroblastomas? and chondromyxoid fibromas. Cancer (Philad.), 12, 1142-1157.

List, C. F. (1943). Osteochondromas arising from the base of the skull. Surg. Gynec. Obstet., 76, 480-492.

Maximow, A. A. (Quoted by Stephenson, 1952).

Maximow, A. A., and Bloom, W. (1942). (Quoted by Gorman, 1960). Textbook of Histology, 4th ed. Saunders: Philadelphia.

Money, R. A. (1943). Solitary intracranial chondroma, Med.J. Aust., 1, 181-183.

Obrador, S., and Soto, F. (1953). Condroma frontal de la noz del cerebro. Rev. clin. esp. 51, 257-260.

O'Neal, L. W., and Ackerman, L. V. (1952). Chondrosarcoma of bone. Cancer (Philad.), 5, 551-577.

Ramamurthi, B., Iyer, C. G. S., and Vedachalam, S. P. (1961). Intracranial meningeal chondroma. J. Neurosurg., 18, 826-828.

Raskind, R., and Grant, S. (1966). Primary mesenchymal chondrosarcoma of the cerebrum. J. Neurosurg., 24, 676-678.

Roukkula, M. (1964). Roentgenologic findings in chondromas of the pontine angle. Acta radiol. Diagn., 2, 120-128.

Russell, D. S., and Ellis, R. W. B. (1933). Circumscribed cerebral tumours in young infants. Arch. dis. Childh, 8, 329-342.

Siris, J. H., and Angrist, A. (1942). Chondroblastic meningiomas. Amer.J. Surg., 57, 162-167. 
Smitt, W. G. S. (1929). Uber intrakraniale Chondrome. Van Wagenen, W. P. (1934). Verified brain tumors-end Dtsch.Z. Nervenheilk., 109, 170-177.

Sperling, S. J., and Alpers, B. J. (1936). Lipoma and osteolipoma of brain. J. nerv. ment. Dis., 83, 13-21.

Stephenson, K. L. (1952). The production of ectopic cartilage. Plast. reconstr. Surg., 9, 302-320. results of 149 cases eight years after operation. $J$. Amer. med Ass., 102, 1454-1458.

Verbrugghen, A., and Learmonth, J. R. (1932). Chondroma of the falx cerebri. Report of a case.J. nerv. ment. Dis., 76, 463-466. 